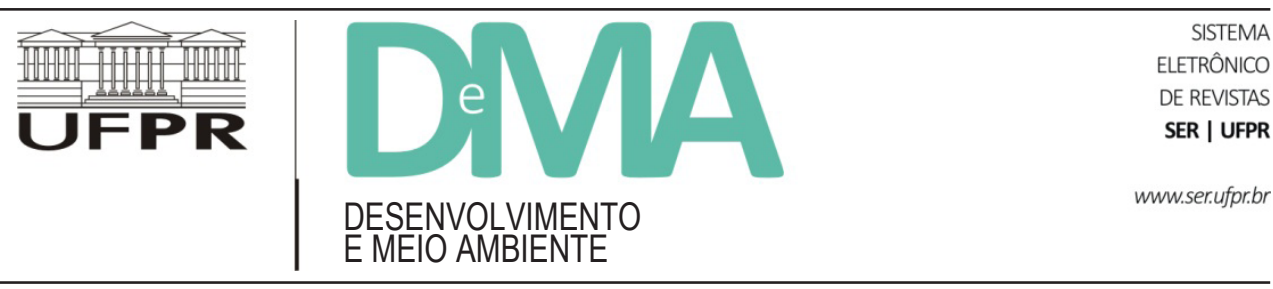

\title{
Sistemas agroflorestais multiestrata e a legislação ambiental brasileira: desafios e soluções
}

\section{Agroforestry Multistrata Systems and the Brazilian Environmental Law: Challenges and Solutions}

\author{
Martin EWERT ${ }^{*}$, Giorgini Augusto VENTURIERI ${ }^{2}$, Walter STEENBOCK ${ }^{3}$, Carlos Eduardo Sicoli SEOANE 4 \\ ${ }^{1}$ Programa de Pós-Graduação em Agroecossistemas, Universidade Federal de Santa Catarina (UFSC), Florianópolis, SC, Brasil. \\ ${ }^{2}$ Universidade Federal de Santa Catarina (UFSC), Florianópolis, SC, Brasil. \\ ${ }^{3}$ Instituto Chico Mendes de Conservação da Biodiversidade (ICMBio), Itajaí, SC, Brasil. \\ ${ }^{4}$ Empresa Brasileira de Pesquisa Agropecuária - Embrapa Florestas, Colombo, PR, Brasil. \\ *E-mail de contato: nitram.ewert@gmail.com
}

Artigo recebido em 20 de fevereiro de 2015, versão final aceita em 9 de abril de 2016.

RESUMO: Imerso no universo de pesquisa das comunidades tradicionais associadas à Cooperafloresta - associação de agricultores agroflorestais localizada nos municípios de Adrianópolis e Bocaiúva do Sul/Paraná e Barra do Turvo/São Paulo -, este artigo apresenta uma discussão dialética sobre os desafios e soluções da vigente legislação ambiental brasileira para a prática dos sistemas agroflorestais. Observa-se que o contexto atual é a pouca presença de políticas ambientais e regulamentação da legislação que os favoreçam no país. Para identificar e descrever o arcabouço legal das agroflorestas na lei, a metodologia foi baseada em um estudo de caso, revisão bibliográfica e observação participante. Com base nas experiências agroflorestais da Cooperafloresta, aponta-se que os principais protagonistas da conservação ambiental são as famílias agricultoras praticantes de agroflorestas. Portanto, defende-se a formação de políticas públicas como as do Programa de Aquisição de Alimentos (PAA), Pagamento por Serviços Ambientais (PSA) e o Sistema Participativo de Garantia (SPG) para a fixação, valorização, empoderamento e melhoria da qualidade de vida dessas famílias para a superação da problemática socioeconômica-ambiental. Conclui-se que há arcabouço legal para a compatibilização do uso de sistemas agroflorestais com a conservação ambiental e o uso de práticas agrícolas adequadas aos objetivos das áreas legalmente protegidas.

Palavras-chave: Cooperafloresta; conservação ambiental; políticas públicas.

ABSTRACT: Immersed in the research universe of traditional communities associated with Cooperafloresta-association of agroforestry farmers located in the municipalities of Adrianópolis and Bocaiúva do Sul/Paraná, and Barra do Turvo/São Paulo - this paper presents a dialectical discussion of challenges and solutions of the current Brazilian environmental laws for agroforestry practice. The current context is the lack of presence of environmental policies and regulations in favor of the legislation in the country. To identify and describe the legal agroforestry 
framework in the law, the methodology was based on a case study, literature review and participant observation. Based on the experiences of Cooperafloresta's agroforestry, the main protagonists of environmental conservation were pointed out to be farming families practicing agroforestry. Therefore, the formation of public policies such as the Acquisition of Food Program (PAA), Payment for Environmental Services (PES), and Participatory Guarantee System (SPG), for fixation, salutation, empowerment and increase in quality of life of those families is supported to overcome the socio-economic problematic they are facing. It was concluded that there is legal support for the compatibility of environmental conservation on legally protected areas with the use of AFS's while using adequate agricultural practices.

Keywords: Cooperafloresta; environmental conservation; public policies.

\section{Introdução}

Existem evidências de que o planeta e suas paisagens estão em uma trajetória insustentável, especialmente as paisagens cobertas com florestas tropicais, convertidas em áreas agrícolas em um ritmo alarmante (Steenbock et al., 2013a). O futuro das paisagens florestais tropicais, e também o da humanidade como um todo, depende da visão que se terá para guiar as atividades humanas em direção à sustentabilidade (Wu, 2013). Na atual necessidade de desenvolver sistemas sustentáveis de produção de alimentos, se destacam os sistemas agroflorestais multiestratificados, popularmente denominados agroflorestas, que incluem práticas de uso e manejo agrícola com a presença do componente arbóreo, da diversidade de espécies e de grande produção de biomassa, onde a composição de espécies busca maximizar a oferta de luz e de nutrientes, tanto na escala horizontal quanto na vertical. Agroflorestas são utilizadas em várias regiões do mundo, predominando nos trópicos e podendo ocorrer em climas temperados. No Brasil, predominam na Amazônia Ocidental, no sul da Bahia e na região do Vale do Ribeira paulista e paranaense (Froufe \& Seoane, 2011a). É nessa última região citada, conhecida por apresentar o mais baixo Índice de Desenvolvimento Humano - IDH - do Estado de São Paulo, que se encontra uma forte experiência em agroflorestas, levada à frente pela Cooperafloresta (Associação dos Agricultores Agroflorestais de Barra do Turvo e Adrianópolis). Atualmente, reúne 130 famílias que, associadas, têm objetivos de inclusão social; recuperação ambiental; valorização dos saberes tradicionais e práticas de agrofloresta (Cooperafloresta, 2012). Sua história inicia em meados da década de 1996, quando duas famílias de agricultores decidem aplicar técnicas de sistemas agroflorestais sucessionais multiestratificados com base em princípios agroecológicos e de forma participativa.

Essas agroflorestas emergem como uma das vertentes da agroecologia, rompendo a lógica de adoção de um sistema convencional de produção definido em "pacote tecnológico", geralmente oferecido pelos órgãos de assistência técnica, e optando pela aplicação de um jeito simples de cultivar. Essa conversão agroecológica ocorre em um processo gradual de transição de sistemas pouco diversificados e dependentes de grande consumo energético para um sistema que copia a dinâmica da natureza por meio de uma ecologia cultivada.

Diante dessa perspectiva, se tem o entendimento de que, na agrofloresta, o ser humano faz parte da natureza e se apresenta como um sistema fortemente autorregulado pelo ecossistema. Logo, a agrofloresta é radicalmente diferente da agricultura convencional de larga escala - que utiliza insumos químicos e defensivos agrícolas em sistema de monocultura -, principalmente porque obedece a dinâmica de sucessão natural da floresta, cultivando 
e manejando de modo a aumentar a vida, a manutenção da fertilidade do solo, a quantidade de água e a biodiversidade do lugar (Nair, 1993; Götsch, 1995; Peneireiro, 1999; Fearnside, 2009; Dubois, 2009). Destacam-se ainda a capacidade de manter bons níveis de produção ao longo prazo, otimizando de modo benéfico as interações entre componentes arbóreos, criação de animais e cultivos anuais, aumentando gradativamente a diversidade da produção e firmando uma tendência de substituição das atividades agrícolas convencionais (Nair, 1993; Smith, 1998; Homma et al., 2009).

A agrofloresta é um plantio intencionalmente biodiverso que, obedecendo a dinâmica sucessional da floresta, culmina em um sistema sofisticado de domesticação da paisagem e de espécies (Froufe \& Seoane, 2011a; Seoane et al., 2012; Steenbock et al., 2013, Venturieri, 2013), que pode vir a ser instrumento de conservação ambiental e provedor de serviços ambientais (Froufe \& Seoane, 2011b; Steenbock et al., 2013a; Ewert, 2014). Dentro desse contexto, as agroflorestas se incluem em uma multiplicidade de formas de domesticação das paisagens e de sistemas de cultivo muito antigos praticados por povos tradicionais, caboclos, índios e caiçaras (Clement1992a, 1992b, 1999; Balée, 2008; Venturieri, 2013) por meio dos ciclos de roças, técnicas de manejo da floresta, uso de coivara, que promovem ao longo do tempo paisagens formadas por florestas secundárias em diferentes estágios de regeneração e biodiversidade (Siminski \& Fantini, 2007; Siminski, 2011).

Alguns trabalhos examinaram questões socioambientais relacionadas às agroflorestas praticadas pela Cooperafloresta. A partir dessas pesquisas, resultados atestam benefícios ambientais e sociais advindos destas práticas agrícolas em diversas áreas, como, por exemplo, as dinâmicas químicas, físicas e biológicas do solo, a ciclagem de nutrientes e a restauração e manutenção de biodiversidade, entre outros, Brown, et al. (2009); Froufe \& Seoane (2011a; 2011b); Seoane et al. (2012); Ewert et al. (2013); Steenbock et al. (2013a, b, c, d); Seoane et al. (2014); Amaral-Silva et al. (2014).

Seoane et al. (2014a); Ewert (2014) e Amaral-Silva et al. (2014) analisaram a agrofloresta do ponto de vista da sustentabilidade socioambiental e perceberam que as agroflorestas apresentam potencial de promover o serviço ecossistêmico de restauração florestal, em nível local e na paisagem. Além disso, as agroflorestas têm assumido produções e rendimentos diferentes, devido ao manejo que pode variar de uma área para outra, variações na composição botânica, fisionomia da floresta e objetivos do agricultor (Steenbock et al., 2013), influenciando significativamente na qualidade de vida e segurança alimentar dos agricultores agroflorestais.

Frente a essas constatações, surge o questionamento: porque as agroflorestas não estão sendo amplamente utilizadas como estratégia de produção de alimentos, segurança alimentar e instrumento da conservação socioambiental no Brasil?

Um dos aspectos relacionados à possível resposta a este questionamento refere-se à legislação ambiental e às políticas ambientais adotadas no país (Ewert et al., 2013; Ewert, 2014). Considerando estes aspectos e procurando contextualizar a prática agroflorestal no texto da Constituição Federal, observa-se que, além de restaurar processos ecológicos, há o cumprimento da função social. Com isso, aponta-se a constitucionalidade para que as agroflorestas possam receber apoio do Poder Público.

Neste sentido, é preciso lembrar que nenhum instrumento legal é superior ou pode ser contrário ao que propõe a Constituição Federal, que estabelece a questão no caput do Art. 225: 
Todos têm direito ao meio ambiente ecologicamente equilibrado, bem de uso comum do povo e essencial à sadia qualidade de vida, impondo-se ao Poder Público e à coletividade o dever de defendê-lo e preservá-lo para as presentes e futuras gerações (Brasil, 1988).

No $\S 1^{\circ}$, Inciso I, está disposto que "para assegurar a efetividade desse direito, incumbe ao Poder Público preservar e restaurar os processos ecológicos essenciais e prover o manejo ecológico das espécies e ecossistemas".

Já no Art. $5^{\circ}$, Inciso XXIII, é definido que "a propriedade atenderá a sua função social". A definição de função social é dada no Art. 186:

A função social é cumprida quando a propriedade rural atende simultaneamente, segundo critérios e graus de exigência estabelecidos em lei, aos seguintes requisitos: I - aproveitamento racional e adequado;

II - utilização adequada dos recursos naturais disponíveis e preservação do meio ambiente;

III - observância das disposições que regulam as relações de trabalho;

IV - exploração que favoreça o bem-estar dos proprietários e dos trabalhadores; [...]

Por conseguinte, o objetivo principal desse artigo é discutir a legislação ambiental brasileira frente aos usos das práticas agroflorestais na Cooperafloresta, identificando os desafios, dificuldades e fatores de influência para regularização da atividade.

\section{Material e métodos}

A metodologia para este artigo consistiu em um estudo de caso, revisão bibliográfica e observação participante, no qual foi realizado acompanhamento do dia-a-dia dos agricultores, somando um contingente de visita a sete propriedades, atingindo 10 agricultores e dois técnicos da Cooperaflores- ta, com o objetivo de captar as experiências dos mesmos e aprofundar-se na realidade singular dos protagonistas da agrofloresta. Primeiro participando de eventos cotidianos para construir os dados da investigação científica, observando, sobretudo, a relação de homens e mulheres com a natureza, suas percepções da floresta e as práticas de cultivo da agrofloresta. Esse levantamento foi feito entre os meses de junho e setembro de 2013, quando foi realizado o acompanhamento de oficinas, capacitações, mutirões e outras atividades cotidianas na Cooperafloresta, que serviram para enriquecer as informações necessárias para a pesquisa. Utilizou-se também de 12 entrevistas semiestruturadas registradas em um gravador portátil. Ao final, os dados alcançados com o acompanhamento em campo e com as entrevistas semiestruturadas foram confrontados com bibliografia científica sobre a agrofloresta e a legislação ambiental vigente. Foi feito um levantamento da legislação brasileira relevante à prática agroflorestal e agroecológica; contudo, não sendo possível abranger todos os aspectos possíveis da legislação que podem se relacionar a este tema, concentrou-se na atual legislação do Estado de São Paulo, considerada uma das mais avançadas entre os estados brasileiros (Brancalion, 2010), e, sobretudo, a legislação vigente no Município de Barra do Turvo-SP, sede da Cooperafloresta e onde a maior parte das unidades familiares agrícolas está situada.

\subsection{Local de estudo e sistema agrícola estudado}

Neste trabalho, utilizaram-se estudos realizados no Alto Vale do Ribeira, nos municípios de Barra do Turvo, SP, e Adrianópolis, PR, região que apresenta relevo acidentado e altitudes de150m. $\mathrm{O}$ clima é Subtropical Úmido Mesotérmico ( $\mathrm{Cfb}$ 
nas porções mais elevadas e Cfa nas mais baixas, conforme a classificação climática de Köppen), com estação quente e úmida de setembro a março, precipitação média anual variando de $1.500 \mathrm{~mm}$ a $2.000 \mathrm{~mm}$ e temperatura média anual de $21,5^{\circ} \mathrm{C}$ (Rousselet-Gadenne, 2004).

A Região do Vale do Ribeira apresenta 70\% de seu território em remanescentes da Floresta Ombrófila Densa Atlântica (Rousselet-Gadenne, 2004), sendo os usos do solo nos dois principais municípios de atuação da Cooperafloresta, Barra do Turvo e Adrianópolis, extremamente opostos: 53\% em Barra do Turvo e 36\% em Adrianópolis das áreas municipais são cobertas com Mata Atlântica (SOS Mata Atlântica, 2010) e o restante é composto por um mosaico dominado por agricultura de subsistência itinerante baseada em derruba-e-queima e pastagens extensivas e degradadas após o rápido esgotamento dos terrenos (Steenbock et al., 2013a).

A área média das unidades familiares de produção rural associadas à Cooperafloresta é de 25,42 hectares, variando de 0,31 a 371,04 hectares. Em média, tendo como base o ano de 2011, 16\% da área das unidades familiares correspondem a agroflorestas, implantadas em diferentes épocas; $58 \%$ da área são capoeiras; $13 \%$ da área são florestas em estágio avançado de regeneração. Em média, 13\% da área das unidades de produção é utilizada para outros fins, sendo geralmente a área da sede e de pequenas criações (Steenbock et al., 2013b).

No âmbito da Cooperafloresta, os sistemas agroflorestais combinam dois sistemas de manejo e domesticação da paisagem (Seoane et al., 2012). Em um, ocorre o manejo intensivo da vegetação, porque é formador de agrofloresta; no outro, garante a regeneração da capoeira e conserva a floresta para uso futuro, mesclando áreas com maior e menor intensidade de manejo (Steenbock et al., 2013). Assim, pode-se considerar, de forma bem simplificada, que a prática agroflorestal na Cooperafloresta é um processo produtivo de agricultura em capoeiras e florestas.

A agrofloresta pode ser iniciada, por exemplo, em uma área de pasto, ou mesmo em áreas de diferentes estágios de regeneração, como capoeiras, onde são plantadas culturas de crescimento rápido juntamente com espécies arbóreas madeiráveis, "adubadeiras", de todos os tamanhos, bem como frutíferas - exóticas ou nativas - que têm por objetivo preencher vários "andares" da floresta, produzindo alimento e materiais tanto na horizontal quanto na vertical. À medida que a agrofloresta vai se desenvolvendo, estará produzindo alimento e madeira em um agroecossistema com características similares às de uma floresta natural, porém com a composição florística direcionada em parte para o interesse humano (Smith et al., 1998; Balée, 2008; Venturieri, 2013). A diferença é que o agricultor estará fazendo o manejo com o propósito de intensificar a dinâmica de sucessão por meio da poda e supressão que fazem parte dessa técnica de manejo da floresta (Ewert et al., 2013). A grosso modo, as agroflorestas são derrubadas da mesma maneira que ocorre na natureza, abrindo uma clareira para permitir a entrada da luminosidade do sol, permitindo que novas plantas cresçam nesse espaço e intensificando a diversidade de espécies com o plantio intencional.

\section{Resultados e discussão}

$$
\begin{array}{r}
\text { "Não basta que todos sejam iguais } \\
\text { perante a lei. É preciso que a lei seja } \\
\text { igual perante todos". } \\
\text { Salvador Allende }
\end{array}
$$

Há várias legislações nacionais que tangem as questões relacionadas aos sistemas agroflorestais. 
Algumas citam explicitamente os sistemas agroflorestais, outras se referem a tópicos que trazem aos praticantes desafios e soluções, entre elas podendo-se destacar e sendo citadas neste trabalho: a Lei da Mata Atlântica (Lei 11.428/2006c) e um dos decretos que a regulamenta (Decreto 6.660/2008); a Lei de Crimes Ambientais (Lei 9.605/1998); o Novo Código Florestal Brasileiro (Lei 12.651/2012); o Sistema Nacional de Unidades de Conservação da Natureza (Lei 9.985/2002); a Lei da Política Nacional da Agricultura Familiar (Lei 11.326/2006b); a Lei da Nova organização da Presidência da República e Ministérios (Lei 10.683/2003a); a Lei de Incentivos e Ações de Recuperação Florestal e Implantação de Sistemas Agroflorestais (Lei 12.854/2013b); a Lei Nacional de Alimentação Escolar (Lei 11.947/2009a); a Lei Nacional da Produção Orgânica (Lei no ${ }^{\circ}$ 10.831/2003b) e um dos decretos que a regulamenta (Decreto 6.323/2007); a Resolução CONAMA 458/2013a; a Resolução CONAMA 425/2010 e a Resolução CONAMA 369/2006a.

Todas essas leis são elaboradas em um Estado democrático pelo poder legislativo, nos âmbitos Federal, Estadual e Municipal, sob a égide da Constituição Federal. Incumbe ao Poder Executivo, por sua vez, a regulamentação das leis, que ocorre geralmente por meio de decretos regulamentadores. Além disso, na área ambiental, a aplicação de Leis ou Decretos muitas vezes precede detalhamento que é de responsabilidade dos órgãos ambientais executores, como o Ministério do Meio Ambiente (MMA), o Instituto Brasileiro do Meio Ambiente (IBAMA) e o Instituto Chico Mendes de Conservação da Biodiversidade (ICMBio), entre outros, que elaboram instruções normativas ou portarias. Já as Resoluções são divididas em nível Federal, representado pelo Conselho Nacional do Meio Ambiente (CONAMA); Estadual, pelos Conselhos
Estaduais do Meio Ambiente (CONSEMA); e Municipal, pelos Conselhos Municipais de Defesa do Meio Ambiente (CONDEMA). Atualmente, grande parte dos instrumentos legais, na área ambiental, são Resoluções do CONAMA. Vale lembrar que as Leis Municipais devem respeitar as Leis Estaduais que, por sua vez, não podem ser menos restritivas que as Leis Federais nem contrariar a Constituição Federal. Assim como um Decreto, Resolução ou Instrução Normativa não devem ser contraditórias às Leis.

\subsection{As agroflorestas e a legislação ambiental}

Observa-se que as leis são bem generalistas quando indicam o que é legal e o que não é legal e nem sempre uma determinada lei contempla todo o detalhamento necessário sobre o tema. $\mathrm{Na}$ área ambiental, constata-se que os instrumentos legais não foram pensados para regulamentar a lógica de produzir bem, conservar a natureza e valorizar a permanência dos povos em suas terras, independente dos limites de áreas de proteção e áreas produtivas (Froufe \& Seoane, 2011a; Steenbock et al., 2013b; 2013c; Ewert et al., 2013).

Por exemplo, a lei da Mata Atlântica (Lei 11.428/2006c), no Art. $3^{\circ}$, Inciso VIII, considera de Interesse Social "as atividades de manejo agroflorestal sustentável praticadas na pequena propriedade ou posse rural familiar que não descaracterizem a cobertura vegetal e não prejudiquem a função ambiental da área" e aparece como ferramenta de conservação que possibilita a implantação das agroflorestas. Nessa lei, existem boas oportunidades para a agrofloresta que deveriam ser aproveitadas. No entanto, alguns decretos que regulamentam a lei da Mata Atlântica, como o 6.660/2008, estabelecendo a utilização e a proteção desse Bioma, vêm dificultar a prática agroflorestal. No Art. $2^{\circ}$, 
$\S 2^{\circ}$, deste Decreto, consta que fica limitado o corte, a supressão ou a exploração florestal "das áreas de vegetação secundária nos estágios inicial, médio e avançado de regeneração e a exploração ou corte de árvores nativas isoladas provenientes de formações naturais". Aliada a esses decretos, surge a atuação equivocada de órgãos ambientais que muitas vezes é restritiva e punitiva em relação ao estágio de regeneração, ao invés de ser instrutiva e informativa (Siminski \& Fantini, 2007).

Em face desse contexto, enquanto um agricultor convencional tem respaldo legal para utilizar agrotóxicos contra a regeneração natural ou mantê-la na estaca "zero", o agricultor praticante de agroflorestas que estiver no exercício das atividades necessárias no manejo da agrofloresta, caso não tenha registrado o plantio e seguido todos os critérios estabelecidos no Decreto 6.660/2008, pode ser enquadrado em crime ambiental, como, por exemplo, o corte, a supressão e a exploração da vegetação secundária em estágio médio ou avançado de regeneração, previstos na Lei 9.605/1998 - lei de crimes ambientais, Art. 38, que considera como passível de punição: "Destruir ou danificar vegetação primária ou secundária, em estágio avançado ou médio de regeneração, do Bioma Mata Atlântica, ou utilizá-la com infringência das normas de proteção" (Brasil, 1998). Nesse sentido, a lógica da legislação vigente causa severas distorções e diferentes entraves.

Se por um lado é preciso legislação específica para compreender a importância da agrofloresta, por outro lado é necessário que a legislação ambiental reinterprete a agricultura convencional. Em qualquer solo que ficar sem uso, sem manejo, ocorrerá ali o processo de regeneração da vegetação nativa por meio da sucessão natural, isto desde que haja propágulos (sementes, etc.) que o possam colonizar e na ausência de uma severa poluição química. A agricultura convencional impede, por meio de intenso manejo, inclusive com uso de produtos químicos, a regeneração natural, enquanto a agrofloresta possibilita e mesmo incentiva tal regeneração. Dessa forma, a antítese pode ser sentida no questionamento sobre a monocultura ou pasto que está onde antes foi floresta de Mata Atlântica, pois se o agricultor impediu a regeneração da floresta em períodos anteriores, a lei permite que esse agricultor tenha o direito de impedir a regeneração da floresta que regenerar para cultivar e manter sua monocultura ou pasto.

Conforme a Resolução CONAMA 369/2006 e a Resolução CONAMA 425/2010, são possíveis a implantação e o manejo de sistemas agroflorestais em APP, nas pequenas propriedades. O critério de corte e manejo para os agricultores familiares e comunidades tradicionais é definido pela Lei 11.326/2006, que considera agricultor familiar e empreendedor familiar rural aquele que pratica atividades em área rural, possui área menor a quatro módulos fiscais, mão de obra familiar, renda familiar vinculada ao próprio estabelecimento e dirige o estabelecimento ou empreendimento pela própria família. Também são considerados agricultores familiares: silvicultores, aquicultores, extrativistas, pescadores, indígenas, quilombolas e assentados.

Em síntese, a lei da Mata Atlântica (Brasil, 2006c) determina quais os tipos de manejo são permitidos nos diferentes estágios de regeneração. Se o agricultor praticante de agroflorestas, com o intuito de deixar a terra se recuperar, permitir o desenvolvimento de uma capoeira grossa, a lei em um determinado momento proíbe o corte dessa área, conforme a interpretação de estágio de sucessão feita pelos órgãos ambientais. Então, o agricultor praticante de agroflorestas é obrigado a derrubar antes, porque não poderá fazer o manejo quando a capoeira já está estabelecida. Por outro lado, o "não manejo" visando à conservação ambiental é 
visto como a solução mais "viável" na percepção das instituições governamentais no Brasil. Esse aspecto das questões técnicas de manejo causa várias inadequações na aplicação desta legislação em relação às agroflorestas, como, por exemplo, havendo motivo da aplicação de multa por prática de desmatamento quando for realizada a poda ou supressão da agrofloresta para se renovar o sistema, tendo o possível agravante de o manejo estar sendo realizado em áreas de especial proteção.

Além disso, nota-se que faltam pesquisas avaliando as diferentes práticas de manejo utilizadas pelos agricultor praticante de agroflorestas, especialmente em áreas legalmente protegidas. $\mathrm{O}$ Código Florestal que vigorou no Brasil de 1965 a 2012 (Lei 4.471/1965) instituiu áreas específicas para proteção de caráter obrigatório em todo território nacional, denominadas de Área de Preservação Permanente (APP) e Área de Reserva Legal (RL). As APPs dependiam do relevo e da hidrografia de cada propriedade, sendo considerados, entre outros, os topos de morro ou áreas muito declivosas e matas ciliares nas margens dos rios. As RLs foram propostas como percentagens de área das propriedades (20\%, na maior parte do Brasil), onde seria permitido apenas uso para projetos de manejo florestal sustentável, unindo produção com conservação ambiental.

Na última década, as discussões sobre a revisão do Código Florestal propondo mudanças que reduziriam a obrigatoriedade da manutenção e restauração de APPs e RLs causaram forte disputa entre ruralistas e ambientalistas. A principal justificativa é que essas áreas geram prejuízos econômicos aos proprietários das terras, mas, em contrapartida, os benefícios ambientais se refletem para toda a humanidade (Marques et al., 2012). Diante disso, o novo Código Florestal Brasileiro, Lei 12.651/2012, mantém as normas das APPs de preservação e uso sustentável das florestas e demais vegetações do território nacional (Brasil, 2012). Conforme o Art. $3^{\circ}$, Incisos II e III, conceitua APP e RL como:

\begin{abstract}
II - Área de Preservação Permanente: Área protegida, coberta ou não por vegetação nativa, com a função ambiental de preservar os recursos hídricos, a paisagem, a estabilidade geológica e a biodiversidade, facilitar o fluxo gênico de fauna e flora, proteger o solo e assegurar o bem-estar das populações humanas;

III - Reserva Legal: área localizada no interior de uma propriedade ou posse rural, delimitada nos termos do Art. 12, com a função de assegurar o uso econômico de modo sustentável dos recursos naturais do imóvel rural, auxiliar a conservação e a reabilitação dos processos ecológicos e promover a conservação da biodiversidade, bem como o abrigo e a proteção da fauna silvestre e da flora nativa;
\end{abstract}

No âmbito da Cooperafloresta, essas áreas protegidas correspondem a mais da metade da área das propriedades, em parte das quais ocorre manejo agroflorestal, justamente recuperando pastos e áreas degradadas (Silva, 2013; Steenbock et al., 2013b). Compete notar que a legislação ambiental permite o uso de sistemas agroflorestais em Áreas de Preservação Permanente. O próprio Código Florestal define que a supressão ou intervenção da vegetação nativa em APP pode ocorrer se for de utilidade pública, interesse social ou baixo impacto ambiental (Brasil, 2012). Entre as definições que existem na Lei 12.651/2012 e contemplam a agrofloresta, entende-se no Art. $3^{\circ}$, Inciso IX, como interesse social, “exploração agroflorestal sustentável praticada na pequena propriedade ou posse rural familiar ou por povos e comunidades tradicionais, desde que não descaracterize a cobertura vegetal existente e não prejudique a função ambiental da área" (Brasil, 2012).

Na Resolução CONAMA 458/2013, Art. 2º, Inciso IV, entre as definições de baixo impacto 
ambiental inclui-se "exploração agroflorestal e manejo florestal sustentável, comunitário e familiar, incluindo a extração de produtos florestais não madeireiros, desde que não descaracterizem a cobertura vegetal nativa existente nem prejudiquem a função ambiental da área" (Brasil, 2013a).

Ademais, a resolução do CONAMA 425/2010 também determina que a prática agroflorestal é possível nas pequenas propriedades familiares, ou de povos e comunidades tradicionais, desde que não prejudique a função ambiental da propriedade.

As agroflorestas na Cooperafloresta são consideradas de baixo impacto ambiental e de alto interesse social (Steenbock et al., 2013). Com esse respaldo legal, constata-se que é possível implantar agroflorestas em Áreas de Preservação Permanente. Todavia, para regulamentar a agrofloresta, é preciso uma declaração junto ao órgão ambiental competente afirmando ser agricultor familiar ou de comunidade tradicional ou de assentamento da reforma agrária, com a devida inscrição no Cadastro Ambiental Rural (CAR) obrigatória para todas as propriedades e posses rurais, conforme o novo Código Florestal. Para regularizar o CAR, é preciso apresentar os dados do proprietário, comprovação da posse da propriedade e um croqui (planta ou memorial descritivo) apontando o perímetro do imóvel e indicando a localização das APPs e RLs (Brasil, 2012). Salienta-se que cabe ao órgão ambiental competente regularizar as atividades de georreferência e coordenadas geográficas do imóvel previsto no Art. $4^{\circ}$ da Lei 12.651/2012 (Brasil, 2012).

Na prática, aponta-se que a ausência ou inadequação de protocolos e sistemas de cadastro, previstos em instrumentos legais, mas incipientemente estabelecidos pelos órgãos ambientais, tem tornado praticamente inviável a regulamentação das práticas agroflorestais.

\subsection{As agroflorestas e as legislações em produção de alimentos agroecológicos}

É interessante notar que existem incentivos na legislação para promover a agricultura familiar e a alimentação orgânica escolar. Por exemplo, o Programa de Aquisição de Alimentos e o Programa Nacional de Alimentação Escolar, este criado em 2003 e regulamentado pela lei 11.947 de junho de 2009, que dispõe sobre a promoção, a operacionalização e a associação da produção familiar local e o consumo de alimentos em quantidade e qualidade compatíveis com o conceito de segurança alimentar, dando sempre preferência aos produtos orgânicos e agroecológicos. No Art. 14 estabelece que

do total dos recursos financeiros repassados pelo FNDE, no âmbito do PNAE, no mínimo 30\% (trinta por cento) deverão ser utilizados na aquisição de gêneros alimentícios diretamente da agricultura familiar e do empreendedor familiar rural ou de suas organizações, priorizando-se os assentamentos da reforma agrária, as comunidades tradicionais indígenas e comunidades quilombolas.

A lei nacional da produção orgânica $n^{\circ} 10.831$ surgiu em 2003, preocupada com a qualidade dos alimentos e com o meio ambiente. De acordo com a lei, para um produto ser considerado orgânico, deve seguir princípios agroecológicos, conforme o Art. $1^{\circ}$ :

considera-se sistema orgânico de produção agropecuária todo aquele que [...] sempre que possível, utilize métodos culturais, biológicos e mecânicos, em contraposição ao uso de materiais sintéticos, com a eliminação do uso de organismos geneticamente modificados e radiações ionizantes, em qualquer fase do processo de produção, processamento, armazenamento, distribuição e comercialização, e a proteção do meio ambiente (Brasil, 2003b). 
Nota-se que a criação e o detalhamento da lei de produção orgânica são novos, bem como a sua regulamentação e as respectivas Instruções Normativas (IN) mais relevantes para o sistema participativo de garantia. Diferentes INs ordenam a qualidade e a gestão da produção orgânica; por exemplo, a IN n ${ }^{\circ} 19$ dispõe sobre mecanismos de avaliação de conformidade de produção orgânica e estabelece a criação dos Sistemas Participativos de Garantia - SPGs.

Com a crescente oferta e demanda da produção orgânica, surge a necessidade de garantir ou atestar a qualidade dos produtos comercializados com tal padrão, bem como garantir sua segurança e procedência (Caldas, 2012). Diante disso, no Brasil, a qualidade de produtos orgânicos é credenciada pelo MAPA e garantida de três modos diferentes: Certificação por Auditoria, Sistemas Participativos de Garantia e Organização de Controle Social para Venda Direta. Os três compõem o Sistema Brasileiro de Avaliação de Conformidade Orgânica (SISORG). O SISORG, por sua vez, é estruturado para possibilitar relações mais transparentes entre produtor e consumidor (Brasil, 2009b).

Considerada como uma tecnologia social, o sistema participativo de garantia é denominado como um mecanismo de credibilidade que conta com participação solidária de todos os interessados em garantir a qualidade final do produto e do processo de produção (Allemann, 2010). A garantia da qualidade do produto orgânico pode ser atestada por uma Organização de Controle Social (OCS) baseada na confiança do produtor e consumidor, possuindo um processo próprio de garantia em um modelo de co-responsabilidade entre consumidor e produtor (Brasil, 2009b). Todavia, os SPGs, como previstos na Lei 10.831 (Brasil, 2003b) e regulamentados pelo decreto $n^{\circ} 6.323$ (Brasil, 2007), foram criados para integrar organizações não governamentais com organizações governamentais que pudessem efetivamente garantir a qualidade de produtos orgânicos por meio da construção de regras e normas coletivas de cada grupo formado. De modo geral, é um sistema que, baseado na capacidade dos agricultores orgânicos, possa estabelecer mecanismos de controle, verificação e regulação de sua produção (Caldas, 2012). Sua articulação ocorre por meio de um grupo de produtores, juntamente com outros interessados no processo de atestar a qualidade do produto, como: os consumidores, técnicos, organizações sociais, etc., de modo colaborativo e autogestionado.

A formação dos SPGs é composta pelos membros do sistema, que são pessoas físicas ou jurídicas que fazem parte de um grupo como colaboradores ou fornecedores, e ainda composta pelo Organismo Participativo de Avaliação de Conformidade (OPAC), responsável pelas certificações por Auditoria (MAPA, 2008). A grosso modo, é o OPAC que avalia, verifica e atesta o produto orgânico comercializado, emitindo laudo técnico da produção.

O processo de verificação da conformidade ocorre por meio da visita da comissão de avaliação e ainda pela visita de pares. A visita da comissão ocorre quando existe a inclusão de novos fornecedores; na verificação de conformidade dos fornecedores certificados; no acompanhamento da correção de não conformidades; na avaliação do cumprimento das penalidades. A visita de pares é realizada por pessoas mais próximas do fornecedor, bem como pode haver a participação de técnicos e consumidores, fortalecendo a confiança (MAPA, 2008; Allemann, 2010).

Por meio da rede Ecovida de Agroecologia, a Cooperafloresta está inserida no processo de certificação participativa orgânica como estratégia de inserção nos mercados de comercialização e venda coletiva. Costa \& Silva (2012) aponta que 
aproximadamente $55 \%$ do faturamento anual de 2010, referente a $\mathrm{R} \$ 842.000,00$, foi proveniente do Programa de Aquisição de Alimentos (PAA). A política do PAA é um incentivo para que os agricultores continuem desenvolvendo as agroflorestas, pois esse é o canal de comercialização que ainda gera mais renda. Essa política é um incentivo, pois estimula a diversificação de produção (em função da diversificação de itens que procuram comprar), o que pode incentivar sistemas produtivos como as SAFs.

Embora existam as contradições e dificuldades apontadas para a regulamentação de práticas agroflorestais, é a partir do arcabouço legal atualmente existente no Brasil que surgem oportunidades para regulamentar as agroflorestas utilizando o sistema participativo de garantia. Aponta-se como caminho para a adequação das atividades agroflorestais a criação ou adequação de legislações e políticas públicas fundamentadas em SPGs e certificação participativa, associando regulamentação e certificação a partir do monitoramento coletivo das práticas agroflorestais, por diferentes grupos e instituições. Dessa forma, os sistemas agroflorestais poderiam ser regulamentados por meio do SPG, com diversas instituições no OPAC validando a prática agroflorestal e garantindo a permanência dos povos em suas terras, favorecendo os serviços ambientais prestados para a humanidade.

\subsection{As agroflorestas e a legislação de restauração da natureza}

À luz dos resultados das pesquisas realizadas na Cooperafloresta, como por exemplo, Froufe \& Seoane (2011a; 2011b); Steenbock et al. (2013b) e Ewert (2014), é evidente o caráter conservacionista e restaurador destes sistemas produtivos. A Lei
12.854, de 26 de agosto de 2013, fomenta e incentiva ações que promovam a recuperação florestal e a implantação de sistemas agroflorestais em áreas rurais desapropriadas e em áreas degradadas. $\mathrm{O}$ incentivo e fomento de que trata esta lei deverá fornecer alternativas econômicas aos agricultores familiares, em especial, às famílias beneficiárias de programas de assentamento rural, pequenos produtores rurais, quilombolas e indígenas. Estando na divisa entre os Estados do Paraná e São Paulo, a maior parte das unidades familiares dos cooperados da Cooperafloresta está sob a legislação paulista. A Resolução 32, de 03/04/2014 (Secretaria de Meio Ambiente do Estado de São Paulo - SEMA/SP, 2014b), estabelece as diretrizes e orientações para a elaboração, a execução e o monitoramento de Projetos de Restauração Ecológica neste Estado. Cabe aqui, portanto, examinar os critérios e parâmetros de avaliação dos resultados de iniciativas de restauração estabelecidos pela resolução e buscar relacioná-los com o conhecimento existente sobre as agroflorestas em questão.

$\mathrm{Na}$ resolução são considerados métodos de restauração ecológica: I - condução da regeneração natural de espécies nativas; II - plantio de espécies nativas; III - plantio de espécies nativas conjugado com a condução da regeneração natural de espécies nativas; e IV - plantio intercalado de espécies lenhosas, perenes ou de ciclo longo exóticas com nativas de ocorrência regional. Estabeleceu-se pela resolução que nos métodos II e III poderá ser realizado o cultivo intercalar temporário de espécies exóticas herbáceas ou arbustivas sem potencial de invasão, tais como culturas agrícolas anuais ou espécies de adubação verde, como estratégia de manutenção da área a fim de auxiliar o controle de gramíneas com potencial de invasão e favorecer o estabelecimento da vegetação nativa. 
As agroflorestas da Cooperafloresta não se encaixam nos métodos I e II, sendo possível encontrar sobreposições com os métodos III e IV, assemelhando-se sobretudo com o método IV. Neste sentido, tecnicamente pode-se definir o método de restauração "agrofloresta da Cooperafloresta" como um "método V": "Plantio intercalado de espécies lenhosas, perenes ou de ciclo longo exóticas com nativas de ocorrência regional, conjugado tanto com a condução da regeneração natural de espécies nativas quanto com o cultivo intercalar permanente de espécies exóticas herbáceas ou arbustivas, tais como culturas agrícolas e espécies de adubação verde". Note-se que o cultivo intercalar de espécies exóticas, nas agroflorestas, não é temporário, e há uso de espécies exóticas consideradas com potencial de invasão, como a uva-do-japão (Hovenia dulcis).

Outra questão abordada na resolução 32 é a da zona de uso do solo no qual o local a ser restaurado se encontra. Em Áreas de Preservação Permanente, por exemplo, apenas nas pequenas propriedades ou posses rurais familiares é possível restaurar utilizando o método IV (plantio intercalado de espécies arbóreas exóticas e nativas) e, mesmo assim, respeitando-se o limite percentual de até $50 \%$ da área total da APP a ser recomposta. Isto é uma questão importante para as agroflorestas da Cooperafloresta, já que há grande quantidade de suas agroflorestas que se encontram em APP. Há na resolução possibilidades em relação à Reserva Legal, no entanto, esta não é uma questão crítica para as unidades familiares da Cooperafloresta tanto quanto a APP o é.

A Resolução 32 também define os indicadores ecológicos a serem utilizados para o monitoramento das alterações na estrutura e autossustentabilidade do ecossistema em restauração, ao longo de sua trajetória, em direção à condição "não degradada". Tais indicadores são: I - cobertura do solo com ve- getação nativa, em porcentagem; II - densidade de indivíduos nativos regenerantes, em indivíduos por hectare; e III - número de espécies nativas regenerantes, sendo estas definidas como "[...] espécimes vegetais nativos oriundos de regeneração natural, ou seja, que não foram plantados ou semeados pelo restaurador". Tais indicadores não foram analisados em Froufe \& Seoane (2011a; 2011b) ou em Steenbock et al. (2013b), mas são passíveis de serem contemplados em futuras pesquisas.

Em Froufe \& Seoane (2011a) destacou-se nas agroflorestas a ocorrência de 507 indivíduos por hectare de juçara (Euterpe edulis), em comparação com uma média de 270 indivíduos da espécie por hectare nas áreas de capoeira. A espécie tem ao mesmo tempo um potencial financeiro grande e grandes restrições de uso. É um espécime vegetal nativo oriundo da regeneração natural, mas ao mesmo tempo também é plantado e principalmente semeado pelo restaurador (agricultor). Nas agroflorestas, esta espécie é plantada e/ou regenerada em áreas de uso agrícola. Ou seja, o agricultor, em suas áreas de uso produtivo, ao invés de escolhas transgênicas, monoculturais, químicas e outras, escolhe cultivar, em um ambiente florestal de alta riqueza de espécies nativas, uma espécie considerada espécie-chave para a funcionalidade do seu bioma, e encontra grandes barreiras legais. Este é um exemplo da complexidade de interpretação legal que muitas das características da agrofloresta e do seu manejo trazem. Não só a Resolução 32, mas a legislação ambiental brasileira em geral não se mostra adequada para catalisar ou mesmo interpretar a potencialidade restauradora e produtiva das agroflorestas agroecológicas.

Há que salientar que a região onde a Cooperafloresta está desenvolvendo as agroflorestas é uma das mais bem conservadas da Mata Atlântica. Portanto, conforme os resultados demonstram, há 
abundância de propágulos das espécies nativas chegando às agroflorestas e assim enriquecendo estes plantios. Muitos destes propágulos, especialmente das espécies iniciais da sucessão secundária (estrategistas " $r$ "), devem ter sido aleatoriamente dispersados pela região toda e, ao encontrar ambientes propícios nas agroflorestas, se estabeleceram com sucesso. Porém, outros propágulos, principalmente daquelas espécies mais voltadas para as "estratégias K", das fases posteriores da sucessão ecológica, especialmente aquelas com interações zoocóricas $^{1}$, provavelmente tiveram uma dispersão direcionada às agroflorestas (Budowski, 1965; Kageyama \& Castro, 1989). Neste sentido, faltam ainda informações de como se dá a regeneração de agroflorestas em locais onde são mais escassas as fontes de propágulos, como, por exemplo, a maior parte do interior de São Paulo, podendo-se prever uma regeneração na agrofloresta que seja composta por um menor número de espécies "colonizadoras". Sendo estes locais também os mais necessitados de restauração florestal, uma das sugestões possíveis para pesquisas futuras é a de se analisar como se dá a regeneração em agroflorestas instaladas em locais do domínio da floresta semidecídua paulista, onde sejam escassas e longínquas as fontes de propágulos das espécies nativas típicas desta floresta, e comparar estes resultados com aqueles requeridos pela resolução vigente.

A Resolução 32 não prevê a possibilidade de manejo produtivo após o encerramento do projeto de restauração e durante o projeto impõe uma série de regras restritivas. Isto se dá por causa da lógica sob a qual ela foi concebida, se tratando de uma legislação voltada para a restauração e não para a produção. No entanto, um dos maiores entraves para a efetiva restauração das florestas brasileiras é a falta de atração, especialmente em termos financeiros, que os atuais projetos de restauração em voga possuem. Em contrapartida, as agroflorestas estudadas por Froufe \& Seoane (2011a; 2011b); Steenbock et al. (2013b) e Ewert (2014) têm se mostrado atraentes e sustentáveis dos pontos de vista cultural, ambiental, econômico e social. Podemos estar frente a uma oportunidade de, por meio de reformulações da legislação vigente e políticas públicas certeiras, promover a restauração florestal em larga escala, não só nas APP e reservas legais do Estado de São Paulo, mas em todo o Bioma da Mata Atlântica. A agrofloresta, apesar de se basear em conhecimentos milenares (Steenbock et al., 2013a), é uma tecnologia agrícola muito recente e que possui um grande potencial de melhorias a serem alcançadas para a conservação e a restauração dos recursos naturais e ecossistêmicos.

Fica evidente o caráter conservacionista e restaurador das agroflorestas para a biodiversidade local, por sua similaridade em espécies, caráter sucessional, regeneração natural e/ou sub-bosques com as capoeiras estudadas. Apesar de ser clara a sobreposição das agroflorestas com os métodos III e IV da Resolução 32 de 03/04/2014, da Secretaria do Meio Ambiente do Estado de São Paulo, não é possível inseri-la como um dos métodos de restauração ecológica previstos na legislação.

Até recentemente, existiam lacunas quanto à possibilidade de regulamentação do manejo específico de algumas espécies largamente interessantes para serem foco de produção nas agroflorestas da Cooperafloresta. O Art. $9^{\circ}$ da Lei 11.428 de 2006 (Brasil, 2006c) afirma que "a exploração eventual, que não tenha propósito comercial, direto ou indi-

\footnotetext{
1 Modo de dispersão das sementes de uma espécie de planta por animais. Em geral, o transporte das sementes ocorre por aves e roedores
} 
reto, de espécies da flora nativa, para consumo das propriedades ou posses das populações tradicionais ou pequenos produtores rurais, independe de autorização dos órgãos ambientais". Por exemplo, nas agroflorestas da Cooperafloresta hoje em dia existem milhares de indivíduos de juçara (Euterpe edulis Martius).

Entretanto, o fato de a espécie ser considerada em extinção, a partir da Lei 10.683/2003 (Brasil, 2008), torna-a imune ao corte, mesmo em situações que poderiam amplificar sua ocorrência, como no cultivo agroflorestal. Esta questão teve um avanço significativo recentemente. A Resolução SMA n ${ }^{\circ} 14$, de 25/02/2014, estabelece critérios e procedimentos para plantio, coleta e exploração sustentáveis de espécies nativas do Brasil no Bioma Mata Atlântica, no Estado de São Paulo. A resolução legisla apenas sobre as áreas comuns não protegidas e áreas comuns cobertas por mata atlântica, portanto, não abordando as áreas protegidas por legislações específicas, como a reserva legal, área de preservação permanente (APP), unidades de conservação ou respectivas zonas de amortecimento, entre outras. Este fato restringe o uso da legislação para menos da metade da área total de agroflorestas das unidades familiares da Cooperafloresta. No entanto, para os restantes 45\% das agroflorestas da Cooperafloresta, situadas em áreas comuns não protegidas, a Resolução cria instrumentos interessantes que, a depender da eficiência dos agricultores e órgãos públicos envolvidos em utilizá-los, podem viabilizar a exploração sustentável dos atuais e futuros estoques de espécies nativas, plantadas ou intencionalmente regeneradas com fins de produção.

Em relação ao palmito da palmeira juçara (Euterpe edulis), o artigo $1^{\circ}$ define as modalidades de plantio, coleta e exploração sustentáveis em área comum não protegida. A potencial exploração de palmito de juçara nas agroflorestas da Cooperafloresta é da modalidade III, "plantio de exploração de espécies nativas". A Resolução tem como anexo um roteiro de orientação para elaboração de PMFS (Plano de Manejo Florestal Sustentável) específico para o plantio e exploração de palmito (utilização de estipe) da palmeira juçara; o agricultor terá que ter apoio de um técnico responsável e juntos irão levantar e fornecer à SEMA/SP uma grande quantidade de dados, entre estes incluindo: a indicação das coordenadas geográficas da unidade produtiva e das unidades de manejo, a fenologia dos indivíduos adultos, o plano de corte anual do estoque dos indivíduos a serem plantados e a descrição detalhada do meio físico e da vegetação. Também será necessário elaborar um plano de recuperação da população.

Uma das exigências para a exploração é a de se manter ao menos 60 indivíduos reprodutivos por hectare, que é o número de indivíduos reprodutivos necessários para se manter a viabilidade genética populacional da palmeira juçara em populações naturais (Reis et al., 2000; Seoane et al., 2005); no entanto, frente a esta exigência, uma questão importante é averiguar se nas unidades familiares da Cooperafloresta a exploração será economicamente viável. Steenbock et al. (2013b) estudaram 16 agroflorestas e em todas encontraram populações plantadas/regeneradas de juçara; nestas, a juçara foi a que teve o terceiro maior Valor de Importância (VI), superado apenas pela banana (Musa paradisiaca) e a pupunha (Bactrisgasipaes), ambas exóticas; já Froufe e Seoane (2011a) verificaram que a juçara é a segunda espécie mais importante nas agroflorestas, sendo superada em VI apenas pela banana. Froufe \& Seoane (2011a) encontraram uma média de 1.080 e 440 indivíduos de juçara por hectare em agroflorestas de 8 anos e 6 anos, respectivamente, considerando indivíduos com diâmetro à altura 
do peito - DAP - maior ou igual a 5 centímetros. Ainda, Froufe \& Seoane (2011a) levantaram que as propriedades estudadas têm, no total de suas áreas, uma média de 23 mil indivíduos da palmeira juçara. Este conjunto de dados indica a possibilidade de viabilidade econômica da exploração de palmito de acordo com esta exigência.

Uma importante definição trazida na resolução se refere a como proceder se o plantio das espécies nativas a serem exploradas foi realizado, mas não foi cadastrado. Tais plantios poderão ser cadastrados, havendo, neste caso, além das exigências da Resolução para os plantios a serem realizados, a necessidade de um laudo técnico que ateste tratar-se de espécies vegetais nativas plantadas. Aqui reside uma dificuldade de aplicação desta Resolução. No parágrafo único do artigo $1^{\circ}$ da Resolução, semelhantemente ao texto federal, afirma-se ser vedado o corte ou supressão de espécies nativas ameaçadas de extinção provenientes de populações naturais, inclusive para alimentação ou uso na propriedade. Mas como distinguir o indivíduo plantado daquele proveniente de população natural? Tendo como exemplo a palmeira juçara, distinguir estas duas origens, plantado ou "natural", é na prática já dificultoso nos primeiros anos do plantio; no entanto, conforme os indivíduos plantados e naturais tornam-se reprodutivos, há troca genética já na polinização entre indivíduos das duas origens. Com isto são formados os frutos, portanto, de origem mesclada entre nativa e plantada, que ao eventualmente germinar e se estabelecer, irão se tornar plântulas aleatoriamente distribuídas nos solos das agroflorestas e, a partir desta fase, perde-se totalmente o sentido de distingui-las como nativas ou plantadas.

No geral, uma das omissões da autoridade pública, em termos de legislação, é a incorporação da dimensão da sucessão ecológica propositadamente levada a cabo nas propriedades, pois, apesar de as agroflorestas se constituírem na base da produção, da segurança alimentar e da renda dos agricultores, o uso mais comum do solo, em termos de área, é a manutenção de capoeiras, que correspondem a mais da metade da área das unidades familiares. É notável a transformação do uso do solo que a adoção de agroflorestas agroecológicas trouxe e das consequências desta transformação na comunidade vegetal existente nas unidades familiares de produção. $\mathrm{O}$ aspecto em destaque nesta transformação no uso do solo é relacionado às capoeiras, que aumentaram tanto em número e espaço ocupado quanto em tempo de permanência na paisagem, pois, antes da prática agroflorestal, não era comum a manutenção de capoeiras por um ciclo muito mais longo que um a dois anos e, com a adoção de agroflorestas, este ciclo foi muito estendido. Os agricultores identificam nas capoeiras espaços de produção de sementes que serão naturalmente dispersas para as agroflorestas. Também identificam nessas áreas espaços de vida de animais importantes para as agroflorestas, especialmente pássaros e abelhas, que trazem sementes e contribuem na polinização. Essas características são consideradas importantes para o aumento da diversidade e da produção das agroflorestas (Seoane et al., 2012; 2014; Steenbock et al., 2013b). Para a regeneração de capoeiras, por sua vez, o manejo é o "não manejo", algo que não é feito por falta de tempo, recursos ou interesse, mas, sim, intencionalmente e com planejamento, se intencionando acumular biomassa, fertilidade e biodiversidade, que oferecerão condições iniciais otimizadas para as futuras Agroflorestas. As capoeiras são as atuais matrizes da paisagem destas propriedades, sendo encontradas na maior parte da unidade familiar, ocupando aproximadamente quatro vezes a área de agroflorestas (Seoane et al., 2012; 2014; Steenbock et al., 2013b). 


\subsection{Aspectos gerais: entraves, potenciais e desafios}

A emergente discussão sobre a regulamentação da agrofloresta na lei pontua avanços, soluções, dificuldades e especialmente a importância de aliar o saber dos povos da floresta com o conhecimento acadêmico, técnico e popular. Esta pesquisa alerta para a necessidade de adequação ambiental da atual legislação considerada punitiva e restritiva. Os entraves identificados na discussão da legislação ambiental apontam distintos gargalos que impedem o avanço dos SAFs em diferentes esferas. Recomenda-se que essa discussão venha a ser estendida para a esfera legal para poderem ser gerados instrumentos que amparem na prática os sistemas agroflorestais. Alguns gargalos que necessitam ser equacionados dizem respeito ao entendimento sobre os serviços ambientais prestados pelas agroflorestas. Existem ainda muitos desafios que limitam a difusão dos SAFs no Brasil, impedindo seu avanço e sua regulamentação. Destacam-se ainda limitações no caso de cultivo de espécies ameaçadas quanto ao seu manejo e uso, como a juçara (E. edulis), ou outras espécies, como a Araucária (Araucaria angustifolia).

No âmbito da Cooperafloresta, as agroflorestas apontam benefícios para o meio ambiente e para a sociedade. Assim, estes sistemas sugerem que as populações humanas que possuem práticas agrícolas adequadas à sustentabilidade socioambiental são fundamentais para a conservação ambiental e para a recuperação de passivos ambientais na floresta de Mata Atlântica. Entretanto, faltam esforços para expandir os sistemas agroflorestais, difundir conhecimento e técnicas para os pequenos agricultores familiares e populações tradicionais e, sobretudo, falta organização institucional para implementar adequadamente a legislação socioambiental que o Brasil possui.
É nessa lógica que o Sistema Participativo de Garantia pode surgir como alternativa para regulamentar os aspectos da legislação ambiental e viabilizar a inclusão de produtores agroecológicos, proporcionando a credibilidade do produto, principalmente porque um dos pontos chave destas leis é a obrigatoriedade de certificação orgânica e esta lógica do SPG pode ser o modelo para discussão da legislação ambiental.

Tendo isso em vista, o grande desafio é integrar continuamente instituições de pesquisa, órgãos ambientais, agricultor praticante de agroflorestas, consumidores e toda a sociedade em um processo participativo de gestão ambiental, construindo uma nova racionalidade a fim de detalhar regras coletivas que sejam éticas, adequadas à conservação ambiental e aliadas às práticas produtivas.

Desse modo, uma eficiente estratégia para os sistemas agroflorestais é conciliar o seu desenvolvimento e a conservação ou melhoria ambiental em espaços protegidos, garantindo a permanência das populações entendidas como tradicionais, preservando a biodiversidade e valorizando os fatores socioculturais como elementos complementares e não antagônicos. Acredita-se que esse é o grande desafio que permeia as discussões agroflorestais na legislação ambiental e a construção de políticas públicas brasileiras.

O cenário desejável para as próximas décadas é a expansão agroflorestal combinada com a redução da desigualdade social e a promoção dos serviços ambientais. O ponto que se defende aqui é como transformar a agrofloresta em riqueza, bem-estar social, cultural e ambiental como uma estratégia de formação dos instrumentos que configuram o Pagamento por Serviços Ambientais (PSA), servindo de incentivo adicional e subsídio para o desenvolvimento agroflorestal.

Portanto, é preciso considerar a criação de políticas públicas e legislações adequadas à realidade 
da agrofloresta, com o potencial para contribuir efetivamente com a superação da problemática ambiental proveniente da agricultura convencional atual. Espera-se com isso empoderar o movimento das agroflorestas diante de uma grande e urgente transformação. Essa transformação deve ser entendida pela legislação ambiental brasileira.

\section{Conclusão}

A vigente legislação ambiental brasileira tende a ignorar o potencial conservacionista das práticas agroflorestais, favorecendo o modelo de agricultura hegemônico, gerador de enormes custos socioambientais. Além disso, muitas vezes as populações tradicionais são discriminadas e impedidas, pela própria política ambiental, de reproduzir seus saberes e ressignificar modos de vida.

\section{Referências}

Allemann, R. et al. Sistema Participativo de Garantia como Gestão da Qualidade da Agricultura Orgânica no Estado de São Paulo. Revista de Gestão Integrativa em Saúde do trabalho e Meio Ambiente, 5(3), 2010.

Amaral-Silva, J.; Rédua, S.; Seoane, C. E.; Froufe, L. C.; Ewert, M.; Steenbock, W. Conservação ambiental forte alcançada através dos Sistemas Agroflorestais Multiestratificados. Cadernos de Agroecologia, 9, 2014.

Balée, W. Sobre a indigeneidade das paisagens. Revista de Arqueologia, 21(2), 9-23, 2008.

Brancalion, P. H. S. et al. Instrumentos legais podem contribuir para a restauração de Florestas tropicais biodiversas. Revista Árvore, 34(3), 455-470, 2010.

Brasil. Lei n. 4471, de 15 de setembro de 1965. Brasília: Diário Oficial da União de 16 de setembro de 1965.

Brasil. Constituição da República Federativa do Brasil. Brasília: Senado Federal, outubro de 1988. Disponível
Por outro lado, existe o respaldo legal para a utilização de sistemas agroflorestais na esfera da conservação socioambiental, bem como o uso dessas práticas em consonância com os objetivos das áreas legalmente protegidas. A inclusão da perspectiva das populações tradicionais e resistência contra-hegemônica por meio de práticas agrícolas adequadas à conservação ambiental é um caminho seguro para se promover justiça nos âmbitos social, ambiental, cultural e econômico.

\section{Agradecimentos}

As pesquisas apresentadas no artigo foram geradas com o apoio do Projeto Agroflorestas, do Macroprograma 06 da Embrapa, e do Projeto Agroflorestar, da Cooperafloresta, com patrocínio da Petrobrás.

em: <http://www.planalto.gov.br/ccivil_03/constituicao/ constitui\%C3\%A7ao.htm>. Acesso em: 18 jun. 2012.

Brasil. Lei n. 9.605, de 12 de fevereiro de 1998. Brasília: Diário Oficial da União de 12 de fevereiro de 1998.

Brasil. Lei n. 9.985, de 18 de julho de 2000. Brasília: Diário Oficial da União de 22 de agosto de 2002.

Brasil. Lei n. 10.683, de 28 de maio de 2003. Brasília: Diário Oficial da União de 29 de maio de 2003 a.

Brasil. Lei n. 10.831, de 29 de dezembro de 2003. Brasília: Diário oficial da União de30 de dezembro de 2003b.

Brasil. Resolução Conama n. 369, de 28 de março de 2006. Brasília: Diário Oficial da União de 29 de março de 2006a.

Brasil. Lei n. 11.326, 24 de julho de 2006. Brasília: Diário Oficial da União de25 de julho de 2006 b.

Brasil. Lei n. 11.428, de 22 de dezembro de 2006. Brasília: Diário Oficial da União de 23 de dezembro de 2006c. 
Brasil. Decreto n. 6.323, de 23 de dezembro de 2007. Brasília: Diário Oficial da União de 27 de dezembro de 2007.

Brasil. Decreto n. 6.660, de 21 de novembro de 2008. Brasília: Diário Oficial da União de 22 de novembro de 2008.

Brasil. Lei n. 11. 947, de 16 de junho de 2009. Brasília: Diário Oficial da União de 17 de junho de 2009a.

Brasil. Resolução n. 30, de 16 de julho de 2009. Brasília: Diário Oficial da União de 16 de julho de 2009b.

Brasil. Resolução n. 425, de 25 de maio de 2010. Brasília: Diário Oficial da União de 27 de maio de 2010.

Brasil. Lei n. 12.651, de 25 de maio de 2012. Brasília: Diário Oficial da União de 25 de maio de 2012.

Brasil. Resolução n. 458, de 16 de julho de 2013. Brasília: Diário Oficial da União de 18 de julho de 2013a.

Brasil. Lei n. 12.854, de 26 de agosto de 2013. Brasília: Diário Oficial da União de 27 de agosto de 2013b.

Brown, G. G.; Maschio, W.; Froufe, L. C. M. Macrofauna do solo em sistemas Agroflorestais e Mata Atlântica em regeneração nos municípios de Barra do Turvo, SP e Adrianópolis, PR. Embrapa Florestas, 2009. 51 p.

Budowski, G. Distribution of tropical American rain-forest species in the light of successional processes. Turrialba, 15(1), 40-42, 1965.

Caldas, N. V. et al. Certificação de produtos orgânicos: obstáculos de implantação de um Sistema Participativo de Garantia na Andaluzia, Espanha. Revista de Economia e Sociologia Rural, 50(3), 2012.

Clement, C. R. Domesticated palms. Principles, 36(2), 70-78, 1992a.

Clement, C. R. Frutas da Amazônia. Ciência Hoje, 14(83), 28-37, $1992 b$.

Clement, C. R. 1492 and the loss of Amazonian cropgenetic resources. I. The relation between domestication and human population decline. Economic Botany, 53(2), 1999.

Cooperafloresta. Quem somos. Barra do Turvo, 2012. Disponível em: $<$ http://frutosdaagrofloresta.org.br/>. Acesso em: 10 set. 2012.

Costa e Silva, L. As necessidades e fontes de informação para a comercialização de produtos agroecológicos na região metropolitana de Curitiba: um estudo de caso na
Cooperafloresta. Curitiba, Dissertação (Mestrado) - Programa de Pós-Graduação em Ciência, Gestão e Tecnologia da Informação, UFPR, 2012. 151 p.

Dubois, J. C. L. Sistemas agroflorestais na Amazônia: avaliação dos principais avanços e dificuldades em uma trajetória de duas décadas. In: Porro, R. (Ed.). Alternativa agroflorestal na Amazônia em transformação. Brasília: Embrapa Informação Tecnológica, 2009. p. 171-218.

Ewert, M.; Mendes, R.; Rédua, S.; Seoane, C. E. Vozes da permanência: a conservação ambiental alcançada com o sistema da agrofloresta. In: Steenbock, W. et al. (Org.). Agrofloresta, ecologia e sociedade. Curitiba: Kairós, 2013. p. 393-420.

Ewert, M. Incentivos e Limites da legislação ambiental brasileira para os sistemas agroflorestais: o caso Cooperafloresta. Dissertação (Mestrado em Agroecossistemas) - Universidade Federal de Santa Catarina, Florianópolis, 2014. p. 128

Fearnside, P. M. Degradação dos recursos naturais na Amazônia Brasileira: implicações para o uso de sistemas agroflorestais. In: Porro, R. (Ed). Alternativa agroflorestal na Amazônia em transformação. Brasília: Embrapa Informação Tecnológica, 2009. p. 161-170.

Froufe, L. C. M.; Seoane, C. E. S. Levantamento fitossociológico comparativo entre sistemas agroflorestais multiestrato e capoeiras como ferramentas para execução da Reserva Legal. Pesquisa Florestal Brasileira (PFB). Embrapa Floresta, 31(67), 203-225, 2011 a.

Froufe, L. C. M.; Seoane, C. E. S. Potencial de sistemas agroflorestais multiestrato para sequestro de carbono em áreas de ocorrência da floresta de Mata Atlântica. Pesquisa Florestal Brasileira (PFB). Embrapa Floresta, 31(66), 143-154, $2011 b$.

Göscht, E. Break-through in agriculture. Rio de Janeiro: AS-PTA, 1995.

Homma, A. K. O. et al. Evolução e percepção dos Sistemas Agroflorestais desenvolvidos pelos agricultores nipo-brasileiros do município de Tomé-Açu, Estado do Pará. Amazônia: Ciência e Desenvolvimento, Belém, 5(9), 121-151, 2009.

Kageyama, P. Y.; Castro, C. F. A. Sucessão secundária, estrutura genética e plantações de espécies arbóreas nativas. IPEF, 41/42, 83-93, 1989. 
Kitamura, P. C.; Rodrigues, G. S. Valoração em serviços ambientais em sistemas agroflorestais: métodos, problemas e perspectivas. In: Anais do III Congresso Brasileiro de Sistemas Agroflorestais - Embrapa, Manaus, 2000.

MAPA - Ministério da Agricultura, Pecuária e Abastecimento.Produtos orgânicos: Sistemas Participativos de Garantia - SPGs. Brasília, 2008.

Marques, E. et al. Determinantes da decisão de manter área protegidas em terra privadas: o caso das reservas legais do Estado de São Paulo. Ambiente e Sociedade, 15(1), 2012.

Nair, P. K. R. An Introduction to agroforestry. Kenia: Academic Publishers, 1993. 499p.

Peneireiro, F. M. Sistemas agroflorestais dirigidos pela sucessão natural: estudo de caso. Piracicaba, São Paulo, Tese (Mestrado) - ESALQ, 1999.

Reis, M. S. dos; Fantini, A. C.; Nodari, R. O.; Reis, A.; Guerra, M. P.; Mantovani, A. Management and conservationof natural populations in Atlantic rain Forest: the case study of palm heart (Euterpe edulis Martius). Biotropica, 32(4B), 894-902, 2000.

Rousselet-Gadenne, A. Adoption d'innovations agroforestières à Barra do Turvo (São Paulo, Brésil). Cahiers d'Agriculture, 13(5), 391-402, 2004.

SEMA - Secretaria de Meio Ambiente do Estado de São Paulo. Resolução SEMA n. 14, de 25 de janeiro de 2014a. Disponível em: $<$ http://www.ambiente.sp.gov.br/legislacao/ resolucoes-sma/resolucao-sma--2014/> . Acesso em: 18 fev. 2015.

SEMA - Secretaria de Meio Ambiente do Estado de São Paulo.Resolução SEMA n. 32, de 03 de abril de $2014 b$. Disponível em: <http://www.ambiente.sp.gov.br/legislacao/ resolucoes-sma/resolucao-sma-32-2014/>. Acesso em: 18 fev. 2015.

Seoane, C. E. S.; Kageyama, P. Y.; Ribeiro, A.; Matias, R.; Reis, M. S.; Bawa, K.; Sebbenn, A. M. Efeitos da fragmentação florestal sobre a imigração de sementes e estrutura genética temporal de populações de Euterpe edulis Martius. Revista do Instituto Florestal, 17, 23-43, 2005.

Seoane, C. E. S.; Silva, R. O.; Steenbock, W.; Maschio, W.; Pinkuss, I. L., Salmon, L. P. G., Da Luz, R. S. S.; Froufe; L. C. M. Agroflorestas e serviços ambientais: espécies para aumento do ciclo sucessional e para facilitação de fluxo gênico. Revista Brasileira de Agropecuária Sustentável, 2(2), 183-188, 2012.

Seoane, C. E. S.; Froufe, L.C.; Amaral-Silva, J.; Arantes, A.C.V.; Nogueira, R.; Steenbock, W. Conservação ambiental forte alcançada através de sistemas agroflorestais multiestratificados. 1 - Agroflorestas e a restauração ecológica de florestas. Cadernos de Agroecologia, 9(4), 2014.

Silva, R. O. et al. As vozes da floresta e a ecologia de saberes. In: Steenbock, W. Agrofloresta, ecologia e sociedade. 1. ed. Curitiba: Kairós, 2013.

Siminski, A. Secondary Forest Succession in the Mata Atlantica, Brazil: Floristic and Phytosociological Trends. International Scholarly Research Network Ecology, 2011. p. 1-19.

Siminski, A.; Fantini, A. C. Roça-de-toco: uso de recursos florestais e dinâmica da paisagem rural no Litoral de Santa Catarina. Ciência Rural, 37(3), 1-10, 2007.

Smith, N. J. H. et al. Agroforestry experiences in the Brazilian Amazon: constraints and opportunities: pilot program to conserve the Brazilian rain forest. Agricultural System, 21, 270-310, 1998.

SOS Mata Atlântica/INPE. 2010. Disponível em: <http:// mapas.sosma.org.br/site_media/download/atlas-relatorio2008-2010parcial.pdf>. Acesso em: 22 nov. 2013.

Steenbock, W. et al. (Org.). Agrofloresta, ecologia e sociedade. 1. ed. Curitiba: Kairós, 2013. 422 p.

Steenbock, W. et al. Agrofloresta: aprendendo a produzir com a natureza. Curitiba, 2013a.

Steenbock, W. et al. Agroflorestas e sistemas agroflorestais no espaço e no tempo. In: Steenbock, W. et al. Agrofloresta, ecologia e sociedade. 1. ed. Curitiba: Kairós, 2013 b.

Steenbock, W. et al. Geração e uso de indicadores e monitoramento de agrofloresta por agricultores associados à Cooperafloresta. In: Steenbock, W. et al. Agrofloresta, ecologia e sociedade. 1. ed. Curitiba: Kairós, 2013c.

Steenbock, W. et al. Características estruturais das agroflorestas desenvolvidas no âmbito da Cooperafloresta. In: Steenbock, W. et al. Agrofloresta, ecologia e sociedade. 1 . ed. Curitiba: Kairós, 2013d.

Venturieri, G. A. Indigenous Strategies Used to Domesticate Plants in Brazilian Amazon. In: Levin, S. A. (Ed.). 
Encyclopedia of Biodiversity. $2^{\text {nd }}$ ed., v. 4. Waltham, MA: Academic Press, 2013. p. 279-292.
Wu, J. Landscape sustainability science: ecosystem services and human well-being in changing landscapes. Landscape Ecology, 28(6), 999-1023, 2013. 